\title{
ANTES DE FRANCISCA: LA BEATA ISABEL BAU- TISTA DE SAN JERÓNIMO O EL ORIGEN DE UN PROYECTO REFORMISTA SEGADO POR LA IN- QUISICIÓN TOLEDANA EN EL SIGLO XVI
}

\author{
Elvira M. MELIÁN
}

Recibido: 29/0122012

Aceptado: 04/11/2013

RESUMEN: La preservación del legajo de Francisca de los Apóstoles, penitenciada por la Inquisición Toledana en 1578, la sitúa en los anales de las beatas judeoconversas «alumbradas» del siglo XVI. En contraste, su también procesada hermana Isabel Bautista de San Jerónimo, responsable última del proyecto fundacional y reformista causante de sus condenas, permanece en el anonimato. Hoy recuperamos su tenue rastro histórico para brindar cierta justicia a quien, en palabras de Francisca, fue «comparable a San Pedro por sus grandes recursos y por estar dispuesta a cualquier cosa», en la que creyó indispensable «renovación espiritual» de la Iglesia.

PALABRAS CLAVE: Judeoconversos. Inquisición Toledo. Parroquia de Santo Tomé. Beatas siglo XVI. Alumbradismo.

ABSTRACT: The preservation of the trial documents about the Jewish converse Francisca de los Apóstoles, punished by the Toledo's Inquisition in 1578, places her in the annals of «beatas alumbradas» in the XVI Century. On the contrary, her also processed sister Isabel Bautista de San Jerónimo, main responsible for the reforming proposals that led them to condemnation, remains anonymous. We recover her tenuous historical track to bring back some justice to a woman that was, in her sister's words, "as resourceful and ready for anything as San Pedro», in pursuing what she believed indispensable "spiritual renewal») of the Church.

KEYWORDS: Conversos. Toledo's Inquisition. Parish of Santo Tomé. Women «beatas» from XVI century. «Alumbradismo».

\section{INTRODUCCIÓN}

En el mes de Abril de 1578 la beata toledana judeoconversa Francisca de Ávila o de los Apóstoles abjura de levi en un auto de fe con una vela en la mano y una soga al cuello. Tras ser sometida públicamente a cien latigazos, es desterrada por 
tres años de Toledo y cinco leguas a la redonda, y a los 39 años desaparece de cualquier registro histórico ${ }^{1}$. La sentencia será relativamente leve considerando su «arrepentimiento, errores y vanidad»; han transcurrido más de cincuenta años del Edicto de Toledo de 1525 contra los alumbrados, y pretende principalmente ser ejemplarizante para otras mujeres. Cuando perdemos su rastro Francisca proyecta casarse y tener descendencia con otro procesado ${ }^{2}$.

La conservación íntegra de su proceso inquisitorial ha tornado a esta beata en modelo de la espiritualidad de una época ${ }^{3}$, y voz de una forma específica de religiosidad 4 . Procesada entre 1574 y 1578 como «hereje, apóstata, blasfema, execrable, temeraria, atrevida y arrogante, excomulgada y perjura, que fingía revelaciones, éxtasis y apariciones» ${ }^{5}$, ingresa en prisión en octubre de 1575 . Dos años más tarde, tras meses de aislamiento, atribuye a su «ignorancia, locura y vanidad $\rangle^{6}$ sus actos y palabras, renunciando a lo que ha defendido hasta entonces. No aceptará sin embargo que sus errores hayan sido invenciones ni «cosas de mujeres», como sostiene el inquisidor y, aún admitiendo el origen demoniaco de sus raptos y revelaciones, defenderá siempre su ausencia de culpabilidad en la línea de los alumbrados ${ }^{7}$.

En contraste con la notoriedad póstuma de Francisca, su hermana Isabel Bautista de San Jerónimo, también procesada, apenas ha dejado huellas históricas más allá de los testimonios del expediente de la primera que le atañen. Paradojas de la historia, pues gracias al manuscrito de la Halle, donde se recoge la actividad del tribunal de Toledo entre 1575 y 1610, sabemos que Isabel fue, junto al clérigo Miguel Ruiz del Hospital de la Misericordia, la verdadera adalid en la génesis de

${ }^{1}$ Proceso de Francisca de los Apóstoles. Archivo Histórico Nacional. Inquisición. Libro 5, legajo 13. Ha sido parcialmente traducido al inglés en el libro de AHLGREN, G.T. (1992). The Inquisition of Francisca, A sixteenth-century visionary on trial. London: Chicago Press.

2 Esta relación será motivo de una segunda serie de acusaciones de las que se defiende asegurando que con el matrimonio se salvará mejor, dado que todos sus planes anteriores dependían de haber podido fundar un convento de monjas donde ella hubiera mantenido sus votos.

${ }^{3}$ GioRDANO, M.L. (1999). «Proyecto político y aspiraciones reformadoras en las cartas de una beata del siglo XVI en España». Manuscrit, 1, pp. 56-68.

4 Ahlgren, G.T. (2000). «Francisca de los Apóstoles: la voz de una visionaria a favor de la Reforma en el Toledo del siglo XVI». En: GILES, M. (eds). Mujeres en la Inquisición: la persecución del Santo Oficio y el Nuevo Mundo. Barcelona: Martínez Roca, pp. 149-166.

5 Sierra, J. (2005). Procesos en la Inquisición de Toledo (1575-1610). Manuscrito de Halle. Madrid: Trotta, p. 78. Este manuscrito se conserva en Alemania.

${ }^{6}$ Ahlgren, G.T.(1992) p.156.

${ }^{7}$ MarqueZ, A. (1980). Los alumbrados: orígenes y filosofia. Madrid: Taurus. 
acontecimientos resultantes en el procesamiento, encarcelación y castigo posterior de ambas ${ }^{8}$. Dicho manuscrito recoge la condena contra ambas hermanas por «proposiciones de alumbrados heréticas, temerarias, blasfemas, ynjiriosas, arrogantes y peligrosas para las costumbres» añadiéndose en el caso de Isabel Bautista el «haver dicho que tenía muchas y diversas revelaciones» ${ }^{9}$. Asimismo permite colegir que su proceso fue considerablemente más extenso, pues intervinieron sesenta y cinco testigos frente a veintiséis. En coherencia con lo que parece mayor responsabilidad penal Isabel es condenada con mayor severidad que su hermana. Se le añade al castigo la soga, y se amplía su destierro tanto en distancia -Toledo y Madrid y cinco leguas alrededor de ambos-, como en tiempo hasta cinco años-.

El objetivo de este trabajo es rescatar del olvido a la hoy anónima Isabel Bautista de San Jerónimo recreando el mundo que frecuentó durante los años precedentes. Años en que gestó y desplegó un proyecto que, más allá de los humanos extravíos, buscaba mejorar las condiciones materiales de vida para las innumerables mujeres sin recursos durante el empobrecido Toledo del siglo XVI ${ }^{10}$.

\section{LA FAMILIA ÁVILA DE NOVES, TOLEDO.}

El origen converso de la familia Ávila es presumible, aunque durante los interrogatorios Francisca asegurase que la familia materna apellidada Díaz era cristiana vieja «olvidando» los apellidos de sus abuelos, como ocurría con frecuencia en estos procesos ${ }^{11 .}$ Naturales de Noves en Toledo, la beata habla de cinco «hermanos». Si bien en los incompletos documentos parroquiales no aparece su propio registro bautismal ${ }^{12}$, sí he podido localizar el de tres hijos de «Cebrián de Ávila o Cebrián pintor, yerno de Alberto Cerezo, casado con Juana Díaz» ${ }^{13 .}$ Aparecen así la propia Isabel Bautista motivo de este trabajo (31-8-1544) (ANEXO 1), María -en el proceso inquisitorial citada como la beata Mariana de la Cruz- (15-

${ }^{8}$ SiERRA, J. (2005).

${ }^{9}$ SiERra, J (2005) p. 238-239.

${ }^{10}$ MARTín, A. (1989-1990).«En torno al estatuto de la mujer en España en la crisis religiosa del Renacimiento: observantes, beatas, alumbradas». Norba Revista de Historia, 10, pp.155-172.

${ }^{11}$ MARTZ, L. (1988). «Converso families in fifteen and sixteenth century Toledo: the significance of lineage». Sefarda , 48, pp. 117-196.

${ }^{12}$ De 1539.

13 Documentos bautismales conservados en la Parroquia de San Pedro Apóstol de Noves en estado bastante deteriorado como puede apreciarse en los anexos. Agradezco al párroco de la misma su amable acogida y ayuda para consultar documentos privados. 
2-1542) (ANEXo 2) y Carlos Cebrián -en el proceso referido como Cebrián- (19-6$1540)^{14}$.

La familia Ávila trabajaba en Noves para la aristócrata Francisca Sarmiento, viuda desde 1544 del Mariscal de Castilla Fernando de Rivadavia ${ }^{15}$. Tras la muerte de su esposo esta noble permanecerá en el pueblo hasta una fecha posterior a 1550, cuando se muda a Torrejón de Velasco, donde muere en 1581. Verosímilmente el movimiento de los hermanos Ávila a Toledo debió coincidir con este traslado, dado que el padre parece haber emigrado tempranamente a trabajar en Madrid tras enviudar.

Durante el siglo XVI se crearán en Toledo numerosos beaterios de conversas, de los que conservamos registro de al menos siete, si bien parecen haber existido muchos más sumergidos posteriormente en el anonimato ${ }^{16}$. Con frecuencia, desde que Cisneros creara un estamento especial en monasterios como San Juan de la Penitencia para educar a niñas sin dinero en una vida honesta, en estos beaterios se recogían niñas y jóvenes con pocos recursos. Concretamente la parroquia de Santo Tomé, originada en la Judería Mayor estaba poblada por gran número de conversos de pocos medios económicos ${ }^{17}$. Dependiendo de ella encontramos a la antigua sinagoga Santa María la Blanca, reconvertida desde 1550, por disposición del cardenal Silíceo, en Refugio de la Penitencia para mujeres públicas arrepentidas ${ }^{18}$. Allí ingresa Francisca alrededor de 1555, con dieciséis años, para permanecer hasta los veinticuatro, y es posible que también lo hicieran sus hermanas, aunque no se conserven documentos que permitan atestiguarlo. Según las crónicas de Hurtado de Mendoza, en 1576 «Santa María la Blanca» albergaba a «trynta y seis beatas con extrema pobreza, porque viven de sola su labor y limosna, y cierto que no se avia

${ }^{14}$ Otros dos «hermanos» acaso fueron en realidad tíos pues Andrés Cerezo (8/3/1539) se presenta como hijo de Alberto Cerezo, y si del nombrado Blas de Ribera no tenemos registro alguno, el hecho de que ambos vivan posteriormente en Toledo juntos e independientes de los otros cuatro sugiriere similar ascendencia genealógica. Este punto no es demostrable dada la ausencia de gran parte de partidas de bautismo.

${ }^{15}$ VAquero Serrano, M.C. (2010). «Garcilaso traicionado. Vida de Guiomar Carrillo. Sus hijos Lorenzo Laso, María de Jesús y de Guzmán y María Ponce de León». Lemir, 14, pp. 121-203.

16 MARTZ, L. (1997). Relaciones entre conversos y cristianos viejos en Toledo en la Edad Moderna: unas perspectivas distintas [recurso electrónico]. Universidad de Castilla la Mancha, http://biblioteca2.uclm.es/biblioteca/ceclm/artrevistas/toletum/tol37/tol martzrelaciones.pdf

[Consultado: 3-4-2012].

${ }^{17}$ Martz, L y Porres J. (1974). Toledo y los toledanos en 1561. Toledo: Instituto Provincial de Investigaciones y Estudios Toledanos.

${ }^{18}$ ESTEPONA, J. (2005). «El cardenal Silíceo, príncipe español de la contra-reforma». Anales de la Fundación Francisco Elías de Tejada, pp. 41-61. 
de descuidar la gente piadosa de su ayuda, para que por la esterilidad y el hambre no fuesen tentadas de volver a la vida pasada» ${ }^{19}$. El fin era evitar un futuro de pecado sin forzarlas a la vida religiosa, y con este objetivo a cierta edad se les ofrecía la opción de ingresar en un noviciado o retornar al mundo. Ignoramos si esta disyuntiva se les planteó a las hermanas Ávila y/u otras internas de Santa María la Blanca, la cual por cierto se clausurará en 1600 por «falta de arrepentimientos». Lo cierto es que esta filosofía condicionará los proyectos de las beatas, centrados en la salvación espiritual de la mujer descarriada. Dentro de este afán Isabel Bautista llamará a «viudas, solteras y perdidas» al beaterio pues la indigencia es responsable última de la falta de virtud, y Francisca implorará durante sus trances la ayuda de María Magdalena recordándole que fue una mujer pública.

En 1563, ya abandonada la Sinagoga, las hermanas siguen residiendo en la parroquia de Santo Tomé, donde se sostienen económicamente enseñando costura $^{20}$. Para entonces apreciamos en ellas analogías con Isabel de la Cruz, famosa beata condenada en 1529 , y representante del primer alumbradismo ${ }^{21}$. Las declaraciones de esta mujer, definida en los archivos del Santo Oficio como una «mujercilla ignorante y soberbia» inducida por «algunos frailes simples y por ventura herejes, originarán el Edicto de Toledo que define y da entidad oficial a esta herejía ${ }^{22}$. Una y otras tienen procedencia judeoconversa, contarán con el apoyo por miembros de la familia Mendoza -verdaderos benefactores del iluminismo-, y de franciscanos reformados enlazados a su vez con Alcalá de Henares. Compartirán asimismo un discurso que combina la crítica a la iglesia oficial con la defensa de la oración mental como medio para la iluminación, y de la exclusión de la pobreza como preceptiva en la prevención de la quiebra moral ${ }^{23}$. Pero en nuestras protagonistas se añade un misticismo excesivo y extravagante, ya muy alejado del

${ }^{19}$ HuRTADO DE TOlEDO, L. (1576). Memorial de algunas cosas notables que tiene la Imperial Ciudad de Toledo [recurso electrónico] Universidad de Castilla la Mancha, http://biblioteca2.uclm.es/biblioteca/ceclm/Libros/Reltoledo/3PARTEToledo.pdf [Consultado: 4-42012]

${ }^{20}$ Aquí parecen haber convivido los cuatro hermanos de padre y madre antes citados: Francisca, Isabel, Mariana y Cebrián.

${ }^{21}$ MuÑoz, A. (1996). «Madre, maestra, autora de doctrina. Isabel de la Cruz y el alumbradismo toledano del primer tercio de siglo XVI». En SEgURA Griaño, C. (ed). La educación de las mujeres: ¿libertad o subordinación?. Madrid: Asociación Cultural Al-Mudayna, pp. 99-122.

${ }^{22}$ MARQUEZ, A. (1980).

${ }^{23}$ Hamilton, A. (1992). Heresy and mysticism in sixteenth century Spain: The alumbrados. Cambridge: James Clarke Company. 
ascetismo de los franciscanos y del racionalismo de los eramistas ${ }^{24}$ que, como se aprecia en los testimonios del Proceso, será en gran parte responsable del desarrollo ulterior de los acontecimientos.

En las declaraciones de Francisca de los Apóstoles Isabel Bautista es equiparada a «San Pedro» por sus «grandes recursos» y por estar «dispuesta a cualquier $\cos a\rangle^{25}$, y de ellas podemos deducir que tuvo una considerable capacidad de liderazgo y cierta inestabilidad psicológica. En 1570 con 26 años sufre una primera crisis con rasgos histéricos incluyendo «conversiones» en parálisis completa, y deambula por Toledo presa de ausencias, con la consecuente zozobra familiar. Sanará gracias a los exorcismos que le practica el clérigo del Hospital de la Misericordia Miguel Ruiz. Tras esta experiencia Isabel, deudora de una iconografía religiosa de excesos para alcanzar la iluminación ${ }^{26}$, desarrolla una creciente devoción religiosa y una vida de oración, penitencia y auto-mortificación, en la que introducirá paulatinamente a sus dos hermanas. A lo largo de los años las beatas reemplazarán estas prácticas por una muy limitada penitencia corporal, mientras caricaturizan los excesos ortodoxos, y en especial a la eremita y acérrima enemiga de los alumbrados Catalina de Cardona ${ }^{27}$.

Conforme a un tiempo de auténtica eclosión mística Isabel, y posteriormente Francisca, sufrirán trances y revelaciones en imitación de Catalina de Siena, a las que no será ajeno Miguel Ruiz, el otro gran protagonista de esta historia. Este clérigo del Hospital de la Misericordia ${ }^{28}$, natural de Yepes, impartía misas al beaterio de las Gaytanas ensamblado al mismo. Tras diagnosticar a Isabel Bautista de endemoniada la exorciza con autorización del consejo diocesano de la gobernación ${ }^{29}$, lo cual revela que inicialmente era considerado poseedor de las cualidades requeridas a los sacerdotes para esta práctica ${ }^{30}$. Tras curar a Isabel se convierte rápidamente en su confesor, implicándose profundamente con un

${ }^{24}$ ASENCIO, E., (1952). «El eramismo y las corrientes espirituales afines (conversos, franciscanos, italianizantes)». Revista de Filología Española, 36, pp. 31-99.

${ }^{25}$ Ahlgren, G.T. (1992). p.126

${ }^{26}$ BArbeito, M.I. (2002). «Mujeres eremitas y penitentes». Via Spiritu, 9, pp. 185-215.

${ }^{27}$ Cortijo OCAÑA, A. (2002). «Vida de la madre Catalina de Cardona por fray Juan de la Miseria. Un texto hagiográfico desconocido del siglo XVI» (Bancroft Library, UCB, Fernán Núñez Collection, vol. 143)». Dicenda: Cuadernos de Filosofia Hispánica,21, pp. 21-34.

${ }^{28}$ Hurtado De Toledo, L. (1576)

${ }^{29}$ Beltrán de Heredia, L. (1972). Misceláneo IV. Colección de artículos sobre la Historia de la Teología Española 27. Salamanca: Biblioteca de Teólogos Españoles, p.363.

${ }^{30}$ DuQue De MAURA. (sin fecha). Supersticiones de los siglos XVI y XVII y hechizos de Carlos II. Madrid: Saturnino Calleja. Sabiduría, virtud, prudencia y dominio del latín, entre otras. 
proyecto del que será, cuando menos, promotor. Según el testimonio del clérigo Pedro Chacón, a los pocos días de conocer a Isabel Bautista y exorcizarla «cobraron ambos tanta amistad y crédito» que decidieron fundar un monasterio dúplice de clérigos y de monjas, éstas bajo la orden de San Jerónimo emulando a la Penitencia. Otra testigo del proceso, enfermera del Hospital de la Misericordia, refiere que las hermanas acudían dos veces al día al mismo para comulgar, permaneciendo largo tiempo con Miguel Ruiz en sus aposentos o en la Sacristía. Será en esta última donde Isabel experimente sus primeros trances y revelaciones precediendo a sus iniciativas fundacionales.

El manuscrito de Halle nos informa de que Miguel Ruiz fue penitenciado por el mismo proceso de las beatas en una causa vista «fuera de auto» el año de 1578 atribuyéndole «dichos, proposiciones y revelaciones de alumbrados». Será condenado a que «se le lea su sentencia en presencia de doze personas religiosas y oiga la misa que en ella se digere en forma de penitente. Abjuración de levi y reprehensión». La pena incluye además «reclusión por dos años y que en ellos no confiese ni administre sacramentos y perpetuamente no confiese mujeres y que no confiese hombres por espacio de doze años más o menos (sin permiso) de su Illma., y que perpetuamente no exorcize ni saque demonios» ${ }^{31}$. Como en el caso de las hermanas Ávila, desconocemos su destino ulterior.

\section{ROMA: EL PROYECTO Y SUS ACTORES}

Con estos mimbres, y tras escribir una regla monástica, Isabel Bautista parte en solitario para Roma en busca de las necesarias licencias el día de Todos los Santos de 1573. Inicia el viaje con tan solo 28 años de edad y sin consentimiento paterno, por lo que las hermanas se ven obligadas a asegurar a la comunidad toledana que la acompaña una ficticia dama. En el camino tiene nuevas visiones interiores, que describe a los expectantes Miguel y Francisca. En ellas se aparecen el Nazareno, San Ildefonso, y «presencia» la excarcelación del arzobispo de Toledo Bartolomé de la Carranza, para ser nombrado Pontífice.

Carranza, reputado teólogo e influyente personaje de Trento, será víctima del Santo Oficio y tachado de luterano por discrepancias de su libro Comentarios al Catecismo Christiano $^{32}$ con la ortodoxia católica ${ }^{33}$. Sus opiniones religiosas y su doctrina le granjearán la enemistad del inquisidor general Valdés y del dominico

${ }^{31}$ SIERRA, J., (2005). p. 245.

32 Publicado en Amberes en 1558.

${ }^{33}$ Gómez Navarro, M.S. (2002). «El proceso del arzobispo Carranza». En MuÑoz MaChado, S. (ed.) Grandes Procesos en la Historia de España. Barcelona: Crítica, pp. 239-285. 
Melchor Cano entre otros, desembocando en su arresto y traslado a Roma en 1559. En esta ciudad permanecerá retenido durante un proceso que dura prácticamente hasta su muerte en $1576^{34}$. Muchas de las proposiciones del Catecismo, de las cuales deberá abjurar para su absolución, persiguen una reforma moral común con las ideas heréticas de los alumbrados, que en algunas de sus afirmaciones parecían asimilarse al luteranismo ${ }^{35}$.

En su correspondencia las beatas departen sobre el compromiso del Arzobispo a patrocinar su proyecto. Podemos atribuir cierta responsabilidad en esta ilusión al canónigo de la catedral de Toledo Pedro González de Mendoza, enviado a Roma en 1567 por el Cabildo de la ciudad para asistir a Carranza durante su encarcelamiento en el castillo de Sant Ángelo ${ }^{36}$. Este prelado transporta en sus viajes las cartas entre Isabel y Francisca, y si hemos de creer sus afirmaciones, llega a entregar al Arzobispo una de ellas recibiendo su respaldo. Pedro González, descendiente por su línea materna de los Mendoza de Guadalajara, mantendrá hasta la muerte de Carranza la confianza en su absolución y vuelta a Toledo. Según crónicas contemporáneas tan tarde como en Abril de 1576, poco antes su fallecimiento, «habia mandado aderezar las linternas de la Yglesia para las alegrías que en este caso se harían», en la creencia de que ha sido liberado ${ }^{37}$. En conjunto el Cabildo toledano permanecerá fiel al Arzobispo durante años tras su prendimiento, «intercediendo por él en Roma y haciendo procesiones y rogativas públicas por su libertad $\rangle^{38}$.

Otra Mendoza, Leonor, apuntalará a las beatas prácticamente hasta su prendimiento, pese a la oposición frontal de su poderoso hermano el cardenal Gaspar de Mendoza. Tras quedar viuda de Fernando Álvarez Ponce de León, miembro de la familia judeoconversa Álvarez de Toledo y Zapata, Leonor se recluye con capellanes y doncellas en unas casas de su propiedad. Allí constituirá entre 1567 y 1569 el beaterio del Corpus Christi, después denominado Hospital del

34 VÁZQueZ DE PRADA, V. (2009). «Precedentes y entorno histórico del procesamiento de Bartolomé Carranza». Archivo Historia de la Iglesia, pp. 101-121.

${ }^{35}$ VÁzQuez de Prada, V. (2009).

36 Tellechea Idígoras, I. (1977). «Memorias sobre el proceso y muerte del Arzobispo Carranza». Príncipe de Viana, 38, nº146-147 pp. 219-260.

${ }^{37}$ SAlazAR DE Miranda, A. (1788). Vida y sucesos prósperos y adversos de Don Fr. Bartolomé de Carranza y Miranda. Madrid: Imprenta D. Joseph Doblado.

38 Menéndez Pelayo, M. (1995). Historia de los heterodoxos españoles. Eramistas y protestantes. Sectas místicas. Judaizantes y moriscos. Artes mágicas. México: editorial Porrúa, p.211.247 
Corpus Christi o de San Juan de Dios ${ }^{39}$. En este lugar, ubicado entre Santa María la Blanca y la Sinagoga del Tránsito, será frecuentada por sus vecinas Isabel y Francisca, que luchan por crear su propio monasterio. La noble llega a financiar el ingreso de una sirvienta cuando este se abre en julio de 1575 , testigo que las acusará a posteriori de endemoniadas y lectoras de Catalina de Siena, dañándolas profundamente. Aunque se han perdido los legajos del proceso de Isabel con asiduidad encontramos el texto «Issabel, sacado a su processo» en los márgenes de las declaraciones de testigos contra Francisca, cuando el testimonio se refiere a ambas.

En el expediente de Francisca se recoge asimismo el testimonio de un franciscano descalzo de origen converso italiano llamado Juan Bautista, discípulo de Mendoza en Alcalá, misionero en China e implicado en otros procesos contra judeoconversos ${ }^{40}$. En este tipo de relaciones las hermanas se ajustarán a un patrón familiar en el alumbradismo, aunque el testigo, inicialmente gran defensor del proyecto, las abandonará a su suerte durante el interrogatorio, como ocurrirá con todos los estamentos clericales.

Mientras Isabel permanece en Roma la esperan en Santo Tomé, además de sus hermanas, un variopinto grupo de mujeres deseosas de ingresar en el beaterio bajo la influencia de Miguel Ruiz. En el censo de Toledo de 1561 encontramos registro de muchas de estas beatas, posteriormente testigos en el proceso inquisitorial ${ }^{41}, \mathrm{y}$ en su mayor parte vecinas de la parroquia de Santo Tomé y de la colindante de San Román, donde se encontraba el Hospital de la Misericordia ${ }^{42}$. Recordemos que este Hospital estuvo íntimamente ligado desde su fundación al beaterio de las Gaytanas, luego convento agustino, creado gracias a las donaciones de Guiomar de Meneses, viuda de Lope Gaytan, en $1459^{43}$. Debemos a esta noble el traslado del primigenio hospital asistencial desde su desconocido emplazamiento original a San Román, y su ampliación por donación varias propiedades. Éstas incluían varias casas destinadas al beaterio, para las que se abrirán «postigos por donde puedan entrar de las casas a la dicha iglesia las beatas». En este Sagrario abierto al beaterio se

${ }^{39}$ VAQUero SERrano, M.C. (2010).

40 Beltran de Heredia, L., (1972)

${ }^{41}$ MARTZ, L y Porres J. (1974)

${ }^{42} \mathrm{He}$ encontrado como residentes de la parroquia de Santo Tomé a testigos del proceso como María de San Jerónimo y su madre, Magdalena de San Francisco, María López, Juana Jiménez o Evangelista y Francisca de Santiago. En San Román aparecen Catalina de San Francisco y Luisa Aguilera.

${ }^{43}$ HuRTAdO DE TOLEDO, L. (1576) 
producirán los exorcismos de Isabel y otras beatas por Ruiz, y parte de los arrobamientos y trances de ambas ${ }^{44}$.

En Diciembre de 1574, estando en Roma, Isabel Bautista sufre un serio episodio de desánimo ante el retraso de las licencias. Francisca ejerce de sostén emocional. Alentada por sus «visiones» en el Sagrario de la Misericordia, la capilla de Nuestra Señora del Sagrario de la catedral de Toledo o su propio lecho, garantiza a una frustrada Isabel el éxito de una gestión donde se implican directamente Carranza y la misma divinidad. En sus cartas coexisten la nostalgia y preocupación familiar por la ausente, una fina ironía sobre el engaño a su vecindad acerca de las condiciones del viaje, y la crítica abierta a la corrupción de los estamentos eclesiásticos. Pero además del consuelo hay reproches. Francisca reclama a Isabel prudencia en sus «declaraciones descontroladas», a las que responsabiliza de que se le niegue la comunión en Roma, y de la reprimenda recibida por parte de estos influyentes judeoconversos. Aparentemente la viajera ha difundido pródigamente su proyecto de monasterio para recoger «viudas, pecadoras y solteras sin recursos», careciendo de los permisos. «Alcoceres, Herreras y Zapatas», todas familias que han mantenido poder político en Toledo a pesar del edicto de Pureza de Sangre de 1566 serán interrogados sobre estas aseveraciones de Isabel por miembros del clero, con la consiguiente inquietud que transmiten severamente a su hermana ${ }^{45}$.

\section{LA VUELTA A TOLEDO Y EL TRUEQUE DE LA FORTUNA}

Cuando Isabel Bautista regresa de Roma, estimulada tras las nuevas de Pedro González de Mendoza sobre el apoyo Carranza, decide viajar a Madrid para entrevistarse con la noble Isabel Osorio, quien le había prometido apoyo económico antes de partir. La aristócrata se retracta del mismo, dándole a cambio cartas de recomendación para autoridades civiles y eclesiásticas, que se mostrarán ineficaces ${ }^{46}$. Será el primer desengaño de una sucesión ininterrumpida, que no impide la inauguración del beaterio con el respaldo de varios clérigos locales, y

44 Fondo documental del Hospital de la Misericordia. Toledo: Archivo de la Diputación Provincial D.L. M-50644-2000 (6 CD). Aunque no se conserva la carta fundacional ni las constituciones del Hospital y del beaterio, sí existen algunas disposiciones testamentarias originales utilizadas en pleitos posteriores entre las Agustinas y el Hospital que nos permiten inferir algunas de sus prebendas originales luego motivo de contencioso.

${ }^{45}$ MARTZ L. (2003) A network of converse families in early modern Toledo. Ann Harbor: Michigan Press.

${ }^{46} \mathrm{Da}$ a Isabel una carta para la noble Catalina Laso y otra para asesores del Rey. Se conserva correspondencia de Santa Teresa a Isabel Osorio. 
careciendo de licencias. Se ubica en una casa alquilada en lo que hoy es la plaza de San Salvador y tendrá una vida muy corta, entre abril y octubre de 1575. Mariana de la Cruz, hermana no procesada de Isabel y Francisca, será la portera y, según los documentos inquisitoriales, llegan a pernoctar allí 12 mujeres, además de dos niñas, aunque en el momento de su detención permanecen únicamente siete incluyendo a las tres hermanas.

La minúscula parroquia de San Salvador colinda con Santo Tomé y San Román, pero su mayor nivel socioeconómico representa un significativo progreso para las beatas $^{47}$. De hecho todo son buenos augurios en julio de 1575, cuando hasta tres presbíteros ${ }^{48}$ proyectan viajar a Roma en su nombre para solicitar las licencias de una comunidad de curas y una de beatas de San Jerónimo sujetas al ordinario ${ }^{49}$. ¿Por qué entonces el precipitado desenlace de este malogrado proyecto y el proceso inquisitorial? Podemos atribuir parte de la responsabilidad a la imprudencia de unas histriónicas mujeres con escasa preparación intelectual, que no ocultan sospechosos vínculos con profetas falsos y perturbados ${ }^{50}$. Pero indudablemente, el detonante último del proceso será socio-político y religioso.

Es notoria la rigurosa persecución que iniciará la Inquisición a partir de 1529 contra los alumbrados, especialmente del reino de Toledo ${ }^{51}$. El análisis profundo el marco histórico-conceptual del alumbradismo sobrepasa los límites de este estudio de ámbito «intrahistórico», pero durante el siglo XVI la ciudad posee una

${ }^{47}$ MARTZ L., PORRES, J (1974). En el censo de 1561 encontramos numerosos conversos como el propio Pedro Zapata, dueño de la casa donde se instalarán, y a un eclesiástico apellidado Herrera que encaja con el señalado por Francisca en el proceso como vecino y hermano de su prometido Hernando Velasco. La endogamia entre conversos para sus matrimonios era una práctica dominante en el Toledo de esta época.

${ }^{48}$ El franciscano Juan Bautista ya señalado, un párroco de Fonseca llamado Marcos Porras y el capellán de los Reyes Alonso López de la Cuadra.

49 Incluso se redacta un documento notarial hoy desaparecido. No aparece en los protocolos conservados de notarios de San Román o Santo Tomé, profusamente consultados.

${ }^{50} \mathrm{El}$ «profeta» Juan de Dios será un elemento decisivo en convertir en detractores a los mismos clérigos que poco tiempo antes pensaban viajar en su apoyo En connivencia con las beatas utilizará el beaterio para curar a los enfermos con una saliva tornada del color del cielo, mientras la propia Isabel Bautista, poniéndose a sí misma como ejemplo, desaconseja llamar a los médicos considerando las enfermedades como demoníacas. Sin embargo su opinión última sobre Juan de Dios es un misterio, pues según los testigos unas veces daba a entender que era un profeta y otras que era sencillamente un loco. Lo cierto es que, antes de abortarse el proyecto por la Inquisición, y pese a sus deseos fue específicamente vetado por las hermanas para el viaje a Roma previsto en el verano de 1575.

51 LlorCA, B. (1980). La Inquisición española y los alumbrados (1509-1667). Salamanca: Universidad de Salamanca. 
significativa comunidad judeoconversa que, en su conjunto, muestra avidez por una espiritualidad más pura, y busca una renovación religiosa ${ }^{52}$. Las beatas conversas son parte fundamental de la misma. Prueba de ello es su presencia en prácticamente todas las asociaciones religiosas toledanas de la época, aparte de en beaterios creados específicamente por esta colectividad. Sin embargo tras la extensión a los órganos civiles en 1566 del edicto de Silíceo sobre la Pureza de Sangre promulgado en 1547 para las instituciones religiosas, la influencia de los conversos en la ciudad agoniza irreversiblemente. Si a la caída del Arzobispo, la extrema tensión religiosa y consecuente hiperactividad inquisitorial, añadimos la temeridad de unas mujeres que se auto-promulgan abiertamente iluminadas en sacristías y plazas $^{53}$, no sorprende su detención, junto a Miguel Ruiz, el 28 de septiembre de $1575^{54}$. Abandonadas por amigos y mecenas, con ella queda bruscamente cercenado su programa reformista.

En 1578, momento de ser penitenciadas y desaparecer de cualquier registro histórico, la instauración cada vez más rígida de la clausura tras el Concilio de Trento ha segado cualquier proyecto de beaterio de religiosas con proyección social en Toledo. Y el resto ya es historia.

52 MARTZ L. (2003).

53 BeInART, H. (1983). Los conversos ante el tribunal de la Inquisición. Barcelona: Riopiedras.

54 Denunciadas en Noviembre de 1574 por dos antiguas discípulas se les abre un expediente según los cauces arquetípicos de los procesos inquisitoriales del XVII; expediente que no acarreará su detención hasta la declaración de un jesuita confesor de las delatoras casi una año más tarde. 
Antes de Francisca: la beata Isabel Bautista de San Jerónimo o el origen de un proyecto reformista...

Anexo 1. Partida bautismal de la beata Isabel Bautista de San Jerónimo fechada el 31 de Agosto de 1544 en Noves, parcialmente ininteligible: «Isabel...el postrero día del ocho mes del año (...) agua de bautismo Isabel hija de Cebrián pintor y de Juana Díaz tuvieron sus compadres (...) padrinos de pila Andrés de (...) y la mujer de (...). Baptizella yo»

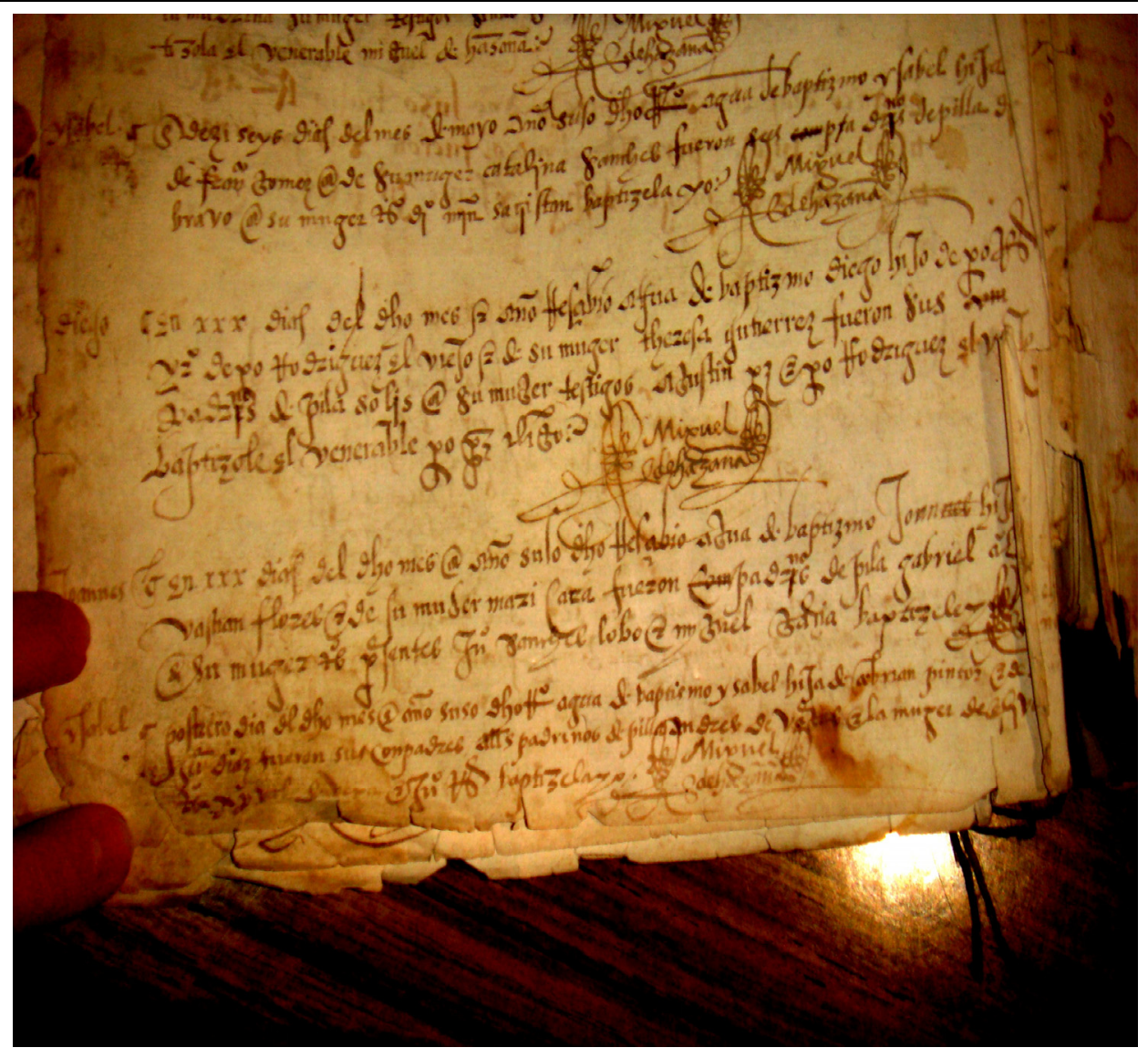


Anexo 2. Partida bautismal de la beata Mariana de de la Cruz fechada el 15 de Mayo de 1542en Noves, parcialmente ininteligible: «en 15 días del dicho mes recibió agua de baptismo maría hija de Cebrián de Abila yerno de Alberto (....) y de Juana Diaz su mujer, fueron sus padrinos Juan del Colina y su mujer (...) y Francisco Alvarez y Gaspar (...) Baptizella yo»

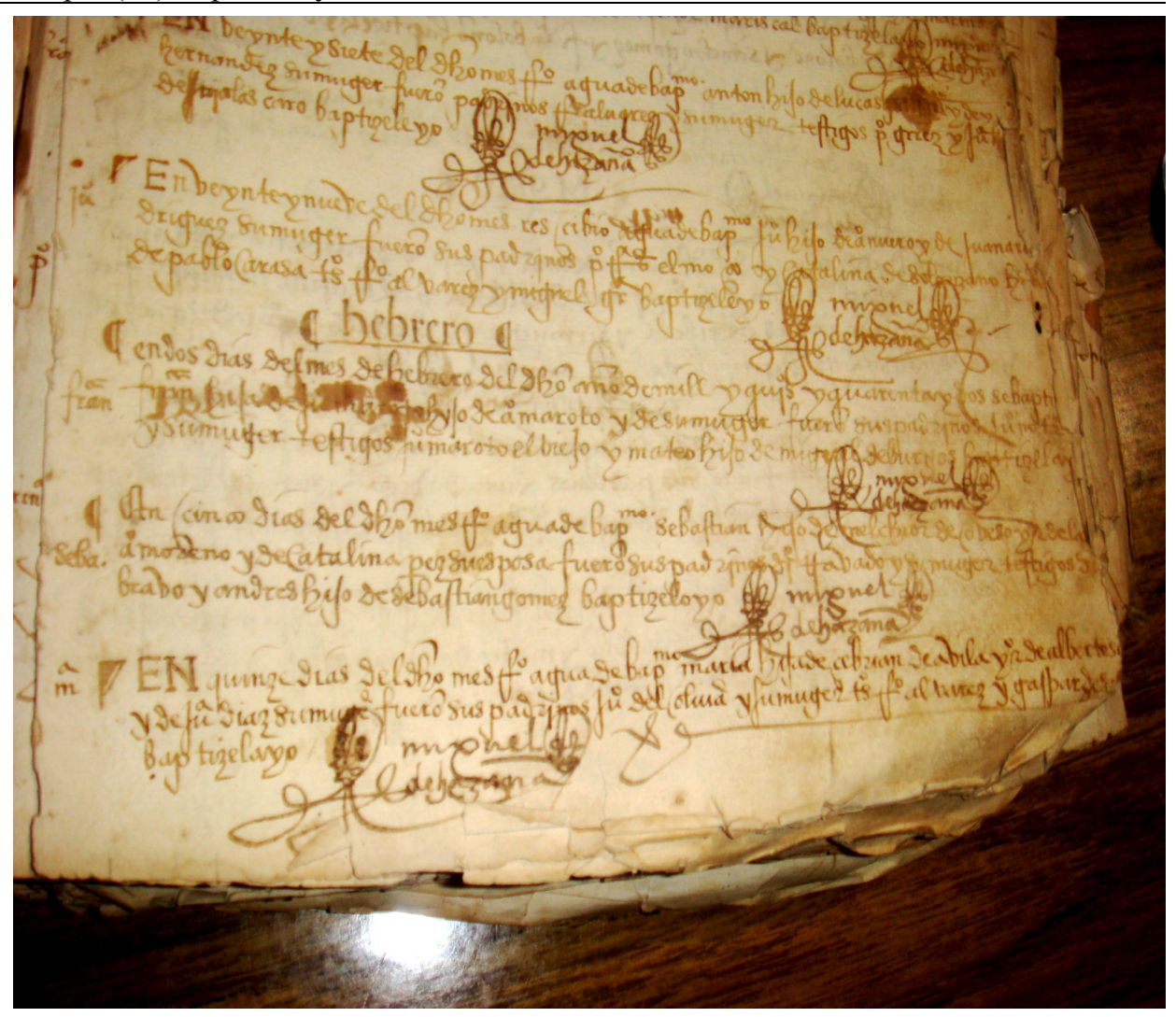

